\title{
Towards structural classification of long non-coding RNAs
}

Karissa Sanbonmatsu*

Los Alamos National Laboratory, Los Alamos, NM 87545

* kys@lanl.gov

phone 505-665-6522

fax 505-665-8934

Keywords: RNA, long non-coding RNA, non-coding RNA, RNA structure, RNA biochemistry

\begin{abstract}
:
While long non-coding RNAs play key roles in disease and development, few structural studies have been performed to date for this emerging class of RNAs. Previous structural studies are reviewed and a pipeline is presented to determine secondary structures of long non-coding RNAs. Similar to riboswitches, experimentally determined secondary structures of long noncoding RNAs for one species may be used to improve sequence/structure alignments for other species. As riboswitches have been classified according to their secondary structure, a similar scheme could be used to classify long non-coding RNAs.
\end{abstract}


Long non-coding RNAs (lncRNAs) have emerged as important players in development, epigenetics, stem cell biology, plant biology, RNA processing, hormone response, cancer and brain function [1-17]. Preceded by the widespread identification of non-coding RNAs in general $[18,19]$ long non-coding RNAs were shown to have high specificity to tissue type and developmental stage [20,21] (also see [22] and references therein). One of the earliest known lncRNAs is Xist ( $\mathrm{X}$ chromosome inactivation stimulated transcript), responsible for $\mathrm{X}$ chromosome inactivation during development [23]. More recently, several lncRNAs have been shown to be critical in HOX gene systems during development [1]. The 1/2sbs-lncRNA controls mRNA decay by hybridizing with mRNA to form a platform for STAU1 protein binding, triggering degradation of mRNA [6]. Other lncRNAs are required for p21 activation [24], stem cell reprogramming [25] and stress response [26].

Although the physiological relevance of many of the reported $(>20,000)$ lncRNAs has not been determined, many lncRNAs have been shown to possess important, visible phenotypes [27]. In addition to Xist, required for dosage compensation, the Braveheart lncRNA has been shown to be required for lineage commitment in cardiomyocytes [2]. FENDRR lncRNA is required for heart, lung and gastrointestinal development [28]. Linc-brn1b is required for neocortex development [28]. The COOLAIR lncRNA is required in A. thaliana for cold-timed flowering [4]. Additionally, the NEAT1 lncRNA has the clear phenotype of being critical for paraspeckle formation [29-31].

While lncRNAs span a wide range of physiological contexts and functions, they have several common characteristics, including length (>200 nts), alternative splicing, poly-adenylation, low 
abundance, lack of protein product, and low sequence identity. Many studies have been performed to identify new lncRNAs, determine their protein partners, and determine their functions (via loss of function knock down and knock out experiments). However, few studies have examined their mechanism at the atomistic level [32]. In the past few years, researchers have been laying the foundation for structure-function studies. Genome-wide studies of RNA secondary structure have been performed, revealing the lncRNAs tend to be more structured than mRNAs, but less structured than ribosomal RNAs [33-39]. Detailed secondary structure studies of complete, intact single lncRNA systems show that some lncRNAs are hierarchically structured with sub-domains containing modular RNA secondary structure motifs [40-42]. Studies of Malat-1 and related lncRNAs show that the 3'-end forms a triple helix, protecting it from RNase degradation [14, 43, 44]. Recent studies have elucidated lncRNA-protein interactions, emphasizing the need for detailed structural studies and mechanistic studies at the molecular and atomistic level $[45,46]$.

LncRNAs tend to have low sequence identity and are often described as non-conserved. We note that some of the most well-studied non-coding RNAs (miRNAs and rRNAs) have very high sequence identity ( $>78 \%$ in nucleic acid sequence identity) [47]. In contrast, many other important classes of non-coding RNAs have relatively low sequence identity (nucleic acid sequence identity of $\sim 50 \%-65 \%$ ), but secondary structures that are conserved across thousands of sequences. For example, riboswitches, which regulate metabolism in bacteria, typically have sequence identities of only $50 \%-65 \%$, but have secondary structures conserved across thousands of species [47]. The U2 and U4 spliceosomal RNAs have sequence identities $<60 \%$ but secondary structures conserved for $>9000$ sequences. The $5 \mathrm{~S}$ ribosomal RNA has sequence 
identity of $\sim 60 \%$ but secondary structure conserved over 229,000 sequences. The group I intron has decidedly low sequence identity $(\sim 36 \%)$ but structure conserved across 60,000 species [47].

RNAs with low sequence identity are difficult to find using conventional search algorithms such as BLAST. However, knowledge of secondary structure dramatically enhances the search success. In the case of riboswitches, the RNA secondary structure was determined for a single species using in vitro chemical probing of the RNA in cell-free reconstituted systems[48-55]. Next, this structure was used as a fingerprint to find the structure in thousands of other species, despite the low sequence identity [56]. The secondary structures determined from cell-free systems by chemical probing were verified by X-ray crystallography [57-61].

To determine the RNA secondary structure of lncRNA molecules, we follow similar strategies to those used to determine the original $16 \mathrm{~S}$ rRNA secondary structure [62-64] and the riboswitches [65] (Fig. 1). Namely, we perform chemical probing experiments to determine nucleotides that are highly mobile and likely to reside in looping regions, as well as those nucleotides with low mobility, likely to participate in Watson-Crick base pairs. To cope with the large RNA size, we employ 3S (Shot-Gun Secondary Structure), which probes the entire RNA first and then probes shorter segments of the RNA in successive rounds of probing [40,66]. By matching signals of short segments with full RNA experiments, we identify modular sub-domains, for which a secondary structure is often readily discernable. The resulting secondary structure can be used to improve existing phylogenetic sequence alignments, and, in principle, can be used to find instances of the lncRNA not previously found in other species. In our studies, we typically begin with either alignments generated by genome browser, or alignments using synteny. We then use 
the initial secondary structure to improve these sequence alignments, focusing on alignment of helical regions. Covariance analysis helps to validate each helix. Next, we use the helices with the most covariant base pairs to further improve the sequence alignment. This process can be performed iteratively, with improved or validated helices enabling improved sequence alignments, and improved sequence alignments enabling more accurate covariant measures.

To demonstrate this principle, we consider the 873 nt steroid receptor RNA activator lncRNA in humans (SRA-1). This lncRNA co-activates the hormone response in human T-47D cells and coimmunoprecipitates with a large number of important proteins, including several hormone receptors (estrogen receptor, progesterone receptor, androgen receptor, glucocorticoid receptor and thyroid receptor) [67-70]. Binding assays in in vitro cell-free reconstituted systems have shown strong binding to the pseudouridinylase Puslp, estrogen receptor, thyroid receptor, the sex reversal factor DAX-1, and the epigenetic factor SHARP. While the primary function of SRA-1 is to co-activate the hormone response, a speculated secondary function involving the binding of SRA-1 to its cognate protein SRAP has recently been shown not to occur (SRA-1 does not bind to SRAP) [71].

Our previous study demonstrated that SRA-1 contains four modular secondary structure subdomains, each containing multiple secondary structure motifs (Fig. 2). The secondary structure was consistent with four different probing techniques (SHAPE, DMS, in-line, and RNase V1). Base pair flips with respect to species were found in the vast majority of helices. Binding studies have shown that SHARP binds to the helix 12 / helix 13 (H12/13) domain [72]. 
Here, to demonstrate the utilize of secondary structure determination, we use the secondary structure of domain IV to improve the phylogenetic alignment of SRA-1 from the Ensembl dataset, in a similar manner to that used by Breaker and co-workers to improve alignments for riboswitch ncRNAs [65]. Figure 3 shows the alignment from Ensembl and the improved alignment of domain IV based on the secondary structure derived form chemical probing. The domain IV secondary structure is present in many of the sequences and covariant base pairs are observed.

This strategy can, in principle, be used to identify orthologs of lncRNAs in other species. Before classifying a lncRNA as a non-conserved RNA, we recommend that the secondary structure be studied and used to search other genomes, in addition to performing BLAST style searches. We note that in vivo probing studies provide important information validating the in vitro structures. In vitro studies are important to establish the ab initio structure because the probing signal in vivo may to be obfuscated by multiple proteins binding to the RNA, as suggested recently (Fig. 4) $[11,12]$. In addition, there are few known cases where an in vitro structure of an intact, individual RNA has been shown to differ from its corresponding in vivo structure. For example, the vast majority of crystallographic structures of RNAs, which are of course determined in vitro, have either (i) been validated in vivo, or (ii) not been disproven in vivo. In the case of riboswitch RNAs, crystallographic data strongly support initial secondary structures determined by chemical probing techniques discussed above. Overall, structure-function studies of lncRNAs are in their infancy and represent an open area of research. Studies of larger lncRNAs (10-100 kB) may open a new area of structural biology and have the potential to reveal novel RNA and RNP mechanisms. Three-dimensional studies of smaller lncRNAs are also an exciting area, especially 
in light of the combination of specific and non-specific RNA-protein interactions thought to be involved in lncRNP complexes [12].

While there are few existing experimentally determined secondary structures of lncRNAs, the future determination of the precise and detailed secondary structure of many lncRNAs may allow immediate classification into type I: highly structured RNAs with sub-domains and complex structural motifs, such as multiway junctions, type II: loosely structured RNAs with multiple stem-loops, but lacking hierarchical domain structure and complex motifs, and type III: unstructured, disordered RNAs, which lack secondary structure. Further classification can proceed upon discovery of many lncRNAs with complex structure in terms of the specific structural motifs that organize the RNA.

\section{Acknowledgements}

The author acknowledges generous support by the LANL LDRD program.

\section{Figure Captions.}

Figure 1. RNA secondary structure determination. (a) One sequence may be consistent with multiple folds. (b) Chemical probing reactivity data helps to lift degeneracy between folds. Multiple sequence alignment help identify covariant base pairs (pink). (c) Pipeline to determine secondary structures of long non-coding RNAs. 
Figure 2. Secondary structure of steroid receptor RNA activator, as determined by $3 \mathrm{~S}$, consists of four sub-domains. The chemical probing reactivity data helped to improve structure/sequence alignments for domain IV.

Figure 3. Example of sequence alignment for domain IV of SRA. (a) Original alignment from Ensembl database. (b) Improved alignment using knowledge of secondary structure.

Figure 4. In vivo probing signals may be obfuscated by protein binding, making it more difficult to distinguish configurations. (a) Schematic of SHAPE probing signal for three-helix junction. (b)-(d) Other configurations that may be consistent with signal (a).

\section{References}

[1] J.L. Rinn, H.Y. Chang, Genome regulation by long noncoding RNAs, Annual review of biochemistry, 81 (2012) 145-166.

[2] C.A. Klattenhoff, J.C. Scheuermann, L.E. Surface, R.K. Bradley, P.A. Fields, M.L. Steinhauser, H. Ding, V.L. Butty, L. Torrey, S. Haas, R. Abo, M. Tabebordbar, R.T. Lee, C.B. Burge, L.A. Boyer, Braveheart, a long noncoding RNA required for cardiovascular lineage commitment, Cell, 152 (2013) 570-583.

[3] T.R. Mercer, J.S. Mattick, Structure and function of long noncoding RNAs in epigenetic regulation, Nat Struct Mol Biol, 20 (2013) 300-307.

[4] S. Swiezewski, F. Liu, A. Magusin, C. Dean, Cold-induced silencing by long antisense transcripts of an Arabidopsis Polycomb target, Nature, 462 (2009) 799-802.

[5] I. Ulitsky, D.P. Bartel, lincRNAs: genomics, evolution, and mechanisms, Cell, 154 (2013) 26-46.

[6] C. Gong, L.E. Maquat, lncRNAs transactivate STAU1-mediated mRNA decay by duplexing with 3' UTRs via Alu elements, Nature, 470 (2011) 284-288.

[7] S. Kaneko, R. Bonasio, R. Saldana-Meyer, T. Yoshida, J. Son, K. Nishino, A. Umezawa, D. Reinberg, Interactions between JARID2 and noncoding RNAs regulate PRC2 recruitment to chromatin, Mol Cell, 53 (2014) 290-300. 
[8] E. Heard, F. Mongelard, D. Arnaud, C. Chureau, C. Vourc'h, P. Avner, Human XIST yeast artificial chromosome transgenes show partial $\mathrm{X}$ inactivation center function in mouse embryonic stem cells, Proc Natl Acad Sci U S A, 96 (1999) 6841-6846.

[9] S.T. da Rocha, V. Boeva, M. Escamilla-Del-Arenal, K. Ancelin, C. Granier, N.R. Matias, S. Sanulli, J. Chow, E. Schulz, C. Picard, S. Kaneko, K. Helin, D. Reinberg, A.F. Stewart, A. Wutz, R. Margueron, E. Heard, Jarid2 Is Implicated in the Initial Xist-Induced Targeting of PRC2 to the Inactive X Chromosome, Mol Cell, 53 (2014) 301-316.

[10] R.M. Boumil, J.T. Lee, Forty years of decoding the silence in X-chromosome inactivation, Human molecular genetics, 10 (2001) 2225-2232.

[11] C. Davidovich, L. Zheng, K.J. Goodrich, T.R. Cech, Promiscuous RNA binding by Polycomb repressive complex 2, Nat Struct Mol Biol, 20 (2013) 1250-1257.

[12] C. Davidovich, X. Wang, C. Cifuentes-Rojas, K.J. Goodrich, A.R. Gooding, J.T. Lee, T.R. Cech, Toward a consensus on the binding specificity and promiscuity of PRC2 for RNA, Molecular Cell, 57 (2015) 552-558.

[13] T.R. Cech, J.A. Steitz, The noncoding RNA revolution-trashing old rules to forge new ones, Cell, 157 (2014) 77-94.

[14] J.A. Brown, D. Bulkley, J. Wang, M.L. Valenstein, T.A. Yario, T.A. Steitz, J.A. Steitz, Structural insights into the stabilization of MALAT1 noncoding RNA by a bipartite triple helix, Nat Struct Mol Biol, 21 (2014) 633-640.

[15] A. Dharap, V.P. Nakka, R. Vemuganti, Effect of focal ischemia on long noncoding RNAs, Stroke, 43 (2012) 2800-2802.

[16] C.P. Ponting, P.L. Oliver, W. Reik, Evolution and functions of long noncoding RNAs, Cell, 136 (2009) 629-641.

[17] T. Derrien, R. Johnson, G. Bussotti, A. Tanzer, S. Djebali, H. Tilgner, G. Guernec, D. Martin, A. Merkel, D.G. Knowles, J. Lagarde, L. Veeravalli, X. Ruan, Y. Ruan, T. Lassmann, P. Carninci, J.B. Brown, L. Lipovich, J.M. Gonzalez, M. Thomas, C.A. Davis, R. Shiekhattar, T.R. Gingeras, T.J. Hubbard, C. Notredame, J. Harrow, R. Guigo, The GENCODE v7 catalog of human long noncoding RNAs: Analysis of their gene structure, evolution, and expression, Genome Res, 22 (2012) 1775-1789.

[18] K. Numata, A. Kanai, R. Saito, S. Kondo, J. Adachi, L.G. Wilming, D.A. Hume, Y. Hayashizaki, M. Tomita, R.G. Group, G.S.L. Members, Identification of putative noncoding RNAs among the RIKEN mouse full-length cDNA collection, Genome Res, 13 (2003) 13011306.

[19] P. Carninci, T. Kasukawa, S. Katayama, J. Gough, M.C. Frith, N. Maeda, R. Oyama, T. Ravasi, B. Lenhard, C. Wells, R. Kodzius, K. Shimokawa, V.B. Bajic, S.E. Brenner, S. Batalov, A.R. Forrest, M. Zavolan, M.J. Davis, L.G. Wilming, V. Aidinis, J.E. Allen, A. AmbesiImpiombato, R. Apweiler, R.N. Aturaliya, T.L. Bailey, M. Bansal, L. Baxter, K.W. Beisel, T. Bersano, H. Bono, A.M. Chalk, K.P. Chiu, V. Choudhary, A. Christoffels, D.R. Clutterbuck, M.L. Crowe, E. Dalla, B.P. Dalrymple, B. de Bono, G. Della Gatta, D. di Bernardo, T. Down, P. Engstrom, M. Fagiolini, G. Faulkner, C.F. Fletcher, T. Fukushima, M. Furuno, S. Futaki, M. Gariboldi, P. Georgii-Hemming, T.R. Gingeras, T. Gojobori, R.E. Green, S. Gustincich, M. Harbers, Y. Hayashi, T.K. Hensch, N. Hirokawa, D. Hill, L. Huminiecki, M. Iacono, K. Ikeo, A. Iwama, T. Ishikawa, M. Jakt, A. Kanapin, M. Katoh, Y. Kawasawa, J. Kelso, H. Kitamura, H. 
Kitano, G. Kollias, S.P. Krishnan, A. Kruger, S.K. Kummerfeld, I.V. Kurochkin, L.F. Lareau, D. Lazarevic, L. Lipovich, J. Liu, S. Liuni, S. McWilliam, M. Madan Babu, M. Madera, L. Marchionni, H. Matsuda, S. Matsuzawa, H. Miki, F. Mignone, S. Miyake, K. Morris, S. Mottagui-Tabar, N. Mulder, N. Nakano, H. Nakauchi, P. Ng, R. Nilsson, S. Nishiguchi, S. Nishikawa, F. Nori, O. Ohara, Y. Okazaki, V. Orlando, K.C. Pang, W.J. Pavan, G. Pavesi, G. Pesole, N. Petrovsky, S. Piazza, J. Reed, J.F. Reid, B.Z. Ring, M. Ringwald, B. Rost, Y. Ruan, S.L. Salzberg, A. Sandelin, C. Schneider, C. Schonbach, K. Sekiguchi, C.A. Semple, S. Seno, L. Sessa, Y. Sheng, Y. Shibata, H. Shimada, K. Shimada, D. Silva, B. Sinclair, S. Sperling, E. Stupka, K. Sugiura, R. Sultana, Y. Takenaka, K. Taki, K. Tammoja, S.L. Tan, S. Tang, M.S. Taylor, J. Tegner, S.A. Teichmann, H.R. Ueda, E. van Nimwegen, R. Verardo, C.L. Wei, K. Yagi, H. Yamanishi, E. Zabarovsky, S. Zhu, A. Zimmer, W. Hide, C. Bult, S.M. Grimmond, R.D. Teasdale, E.T. Liu, V. Brusic, J. Quackenbush, C. Wahlestedt, J.S. Mattick, D.A. Hume, C. Kai, D. Sasaki, Y. Tomaru, S. Fukuda, M. Kanamori-Katayama, M. Suzuki, J. Aoki, T. Arakawa, J. Iida, K. Imamura, M. Itoh, T. Kato, H. Kawaji, N. Kawagashira, T. Kawashima, M. Kojima, S. Kondo, H. Konno, K. Nakano, N. Ninomiya, T. Nishio, M. Okada, C. Plessy, K. Shibata, T. Shiraki, S. Suzuki, M. Tagami, K. Waki, A. Watahiki, Y. Okamura-Oho, H. Suzuki, J. Kawai, Y. Hayashizaki, F. Consortium, R.G.E.R. Group, G. Genome Science, The transcriptional landscape of the mammalian genome, Science, 309 (2005) 1559-1563.

[20] J. Ponjavic, C.P. Ponting, G. Lunter, Functionality or transcriptional noise? Evidence for selection within long noncoding RNAs, Genome Res, 17 (2007) 556-565.

[21] M.E. Dinger, P.P. Amaral, T.R. Mercer, K.C. Pang, S.J. Bruce, B.B. Gardiner, M.E. Askarian-Amiri, K. Ru, G. Solda, C. Simons, S.M. Sunkin, M.L. Crowe, S.M. Grimmond, A.C. Perkins, J.S. Mattick, Long noncoding RNAs in mouse embryonic stem cell pluripotency and differentiation, Genome Res, 18 (2008) 1433-1445.

[22] J.L. Rinn, H.Y. Chang, Genome regulation by long noncoding RNAs, Annu Rev Biochem, 81 (2012) 145-166.

[23] J.T. Lee, R. Jaenisch, The (epi)genetic control of mammalian X-chromosome inactivation, Curr Opin Genet Dev, 7 (1997) 274-280.

[24] M. Huarte, M. Guttman, D. Feldser, M. Garber, M.J. Koziol, D. Kenzelmann-Broz, A.M. Khalil, O. Zuk, I. Amit, M. Rabani, L.D. Attardi, A. Regev, E.S. Lander, T. Jacks, J.L. Rinn, A large intergenic noncoding RNA induced by p53 mediates global gene repression in the p53 response, Cell, 142 (2010) 409-419.

[25] M. Guttman, J. Donaghey, B.W. Carey, M. Garber, J.K. Grenier, G. Munson, G. Young, A.B. Lucas, R. Ach, L. Bruhn, X. Yang, I. Amit, A. Meissner, A. Regev, J.L. Rinn, D.E. Root, E.S. Lander, lincRNAs act in the circuitry controlling pluripotency and differentiation, Nature, 477 (2011) 295-300.

[26] T. Kino, D.E. Hurt, T. Ichijo, N. Nader, G.P. Chrousos, Noncoding RNA gas5 is a growth arrest- and starvation-associated repressor of the glucocorticoid receptor, Sci Signal, 3 (2010) ra8.

[27] L. Li, H.Y. Chang, Physiological roles of long noncoding RNAs: insight from knockout mice, Trends in cell biology, 24 (2014) 594-602.

[28] M. Sauvageau, L.A. Goff, S. Lodato, B. Bonev, A.F. Groff, C. Gerhardinger, D.B. SanchezGomez, E. Hacisuleyman, E. Li, M. Spence, S.C. Liapis, W. Mallard, M. Morse, M.R. Swerdel, M.F. D'Ecclessis, J.C. Moore, V. Lai, G. Gong, G.D. Yancopoulos, D. Frendewey, M. Kellis, 
R.P. Hart, D.M. Valenzuela, P. Arlotta, J.L. Rinn, Multiple knockout mouse models reveal lincRNAs are required for life and brain development, eLife, 2 (2013) e01749.

[29] T. Naganuma, S. Nakagawa, A. Tanigawa, Y.F. Sasaki, N. Goshima, T. Hirose, Alternative 3'-end processing of long noncoding RNA initiates construction of nuclear paraspeckles, EMBO J, 31 (2012) 4020-4034.

[30] S. Nakagawa, T. Hirose, Paraspeckle nuclear bodies--useful uselessness?, Cell Mol Life Sci, 69 (2012) 3027-3036.

[31] Y.T. Sasaki, T. Ideue, M. Sano, T. Mituyama, T. Hirose, MENepsilon/beta noncoding RNAs are essential for structural integrity of nuclear paraspeckles, Proceedings of the National Academy of Sciences of the United States of America, 106 (2009) 2525-2530.

[32] I.V. Novikova, S.P. Hennelly, C.S. Tung, K.Y. Sanbonmatsu, Rise of the RNA machines: exploring the structure of long non-coding RNAs, J Mol Biol, 425 (2013) 3731-3746.

[33] Y. Wan, K. Qu, Q.C. Zhang, R.A. Flynn, O. Manor, Z. Ouyang, J. Zhang, R.C. Spitale, M.P. Snyder, E. Segal, H.Y. Chang, Landscape and variation of RNA secondary structure across the human transcriptome, Nature, 505 (2014) 706-709.

[34] Y. Wan, K. Qu, Z. Ouyang, H.Y. Chang, Genome-wide mapping of RNA structure using nuclease digestion and high-throughput sequencing, Nat Protoc, 8 (2013) 849-869.

[35] Z. Ouyang, M.P. Snyder, H.Y. Chang, SeqFold: genome-scale reconstruction of RNA secondary structure integrating high-throughput sequencing data, Genome Res, 23 (2013) 377387.

[36] Y. Wan, K. Qu, Z. Ouyang, M. Kertesz, J. Li, R. Tibshirani, D.L. Makino, R.C. Nutter, E. Segal, H.Y. Chang, Genome-wide Measurement of RNA Folding Energies, Molecular cell, 48 (2012) 169-181.

[37] M. Kertesz, Y. Wan, E. Mazor, J.L. Rinn, R.C. Nutter, H.Y. Chang, E. Segal, Genome-wide measurement of RNA secondary structure in yeast, Nature, 467 (2010) 103-107.

[38] Y. Ding, Y. Tang, C.K. Kwok, Y. Zhang, P.C. Bevilacqua, S.M. Assmann, In vivo genomewide profiling of RNA secondary structure reveals novel regulatory features, Nature, 505 (2014) 696-700.

[39] S. Rouskin, M. Zubradt, S. Washietl, M. Kellis, J.S. Weissman, Genome-wide probing of RNA structure reveals active unfolding of mRNA structures in vivo, Nature, 505 (2014) 701705.

[40] I.V. Novikova, S.P. Hennelly, K.Y. Sanbonmatsu, Structural architecture of the human long non-coding RNA, steroid receptor RNA activator, Nucleic Acids Res, 40 (2012) 5034-5051.

[41] I.A. Ilik, J.J. Quinn, P. Georgiev, F. Tavares-Cadete, D. Maticzka, S. Toscano, Y. Wan, R.C. Spitale, N. Luscombe, R. Backofen, H.Y. Chang, A. Akhtar, Tandem stem-loops in roX RNAs act together to mediate X chromosome dosage compensation in Drosophila, Mol Cell, 51 (2013) 156-173.

[42] S. Somarowthu, M. Legiewicz, I. Chillon, M. Marcia, F. Liu, A.M. Pyle, HOTAIR forms an intricate and modular secondary structure, Mol Cell, 58 (2015) 353-361.

[43] J.E. Wilusz, C.K. JnBaptiste, L.Y. Lu, C.D. Kuhn, L. Joshua-Tor, P.A. Sharp, A triple helix stabilizes the 3' ends of long noncoding RNAs that lack poly(A) tails, Genes Dev, 26 (2012) 2392-2407. 
[44] J.E. Wilusz, S.M. Freier, D.L. Spector, 3' end processing of a long nuclear-retained noncoding RNA yields a tRNA-like cytoplasmic RNA, Cell, 135 (2008) 919-932.

[45] C. Chu, Q.C. Zhang, S.T. da Rocha, R.A. Flynn, M. Bharadwaj, J.M. Calabrese, T. Magnuson, E. Heard, H.Y. Chang, Systematic discovery of Xist RNA binding proteins, Cell, 161 (2015) 404-416.

[46] R.C. Spitale, R.A. Flynn, Q.C. Zhang, P. Crisalli, B. Lee, J.W. Jung, H.Y. Kuchelmeister, P.J. Batista, E.A. Torre, E.T. Kool, H.Y. Chang, Structural imprints in vivo decode RNA regulatory mechanisms, Nature, 519 (2015) 486-490.

[47] S. Griffiths-Jones, A. Bateman, M. Marshall, A. Khanna, S.R. Eddy, Rfam: an RNA family database, Nucleic Acids Res, 31 (2003) 439-441.

[48] E.E. Regulski, R.R. Breaker, In-line probing analysis of riboswitches, Methods Mol Biol, 419 (2008) 53-67.

[49] W. Winkler, A. Nahvi, R.R. Breaker, Thiamine derivatives bind messenger RNAs directly to regulate bacterial gene expression, Nature, 419 (2002) 952-956.

[50] M. Mandal, B. Boese, J.E. Barrick, W.C. Winkler, R.R. Breaker, Riboswitches control fundamental biochemical pathways in Bacillus subtilis and other bacteria, Cell, 113 (2003) 577586.

[51] M. Mandal, M. Lee, J.E. Barrick, Z. Weinberg, G.M. Emilsson, W.L. Ruzzo, R.R. Breaker, A glycine-dependent riboswitch that uses cooperative binding to control gene expression, Science, 306 (2004) 275-279.

[52] W.C. Winkler, A. Nahvi, A. Roth, J.A. Collins, R.R. Breaker, Control of gene expression by a natural metabolite-responsive ribozyme, Nature, 428 (2004) 281-286.

[53] N. Sudarsan, M.C. Hammond, K.F. Block, R. Welz, J.E. Barrick, A. Roth, R.R. Breaker, Tandem riboswitch architectures exhibit complex gene control functions, Science, 314 (2006) 300-304.

[54] M.T. Cheah, A. Wachter, N. Sudarsan, R.R. Breaker, Control of alternative RNA splicing and gene expression by eukaryotic riboswitches, Nature, 447 (2007) 497-500.

[55] N. Sudarsan, E.R. Lee, Z. Weinberg, R.H. Moy, J.N. Kim, K.H. Link, R.R. Breaker, Riboswitches in eubacteria sense the second messenger cyclic di-GMP, Science, 321 (2008) 411413.

[56] Z. Weinberg, J.E. Barrick, Z. Yao, A. Roth, J.N. Kim, J. Gore, J.X. Wang, E.R. Lee, K.F. Block, N. Sudarsan, S. Neph, M. Tompa, W.L. Ruzzo, R.R. Breaker, Identification of 22 candidate structured RNAs in bacteria using the CMfinder comparative genomics pipeline, Nucleic Acids Res, 35 (2007) 4809-4819.

[57] R.T. Batey, S.D. Gilbert, R.K. Montange, Structure of a natural guanine-responsive riboswitch complexed with the metabolite hypoxanthine, Nature, 432 (2004) 411-415.

[58] R.K. Montange, R.T. Batey, Structure of the S-adenosylmethionine riboswitch regulatory mRNA element, Nature, 441 (2006) 1172-1175.

[59] S.D. Gilbert, R.P. Rambo, D. Van Tyne, R.T. Batey, Structure of the SAM-II riboswitch bound to S-adenosylmethionine, Nat Struct Mol Biol, 15 (2008) 177-182. 
[60] C.D. Stoddard, R.K. Montange, S.P. Hennelly, R.P. Rambo, K.Y. Sanbonmatsu, R.T. Batey, Free state conformational sampling of the SAM-I riboswitch aptamer domain, Structure, 18 (2010) 787-797.

[61] R.K. Montange, R.T. Batey, Riboswitches: emerging themes in RNA structure and function, Annu Rev Biophys, 37 (2008) 117-133.

[62] C.R. Woese, L.J. Magrum, R. Gupta, R.B. Siegel, D.A. Stahl, J. Kop, N. Crawford, J. Brosius, R. Gutell, J.J. Hogan, H.F. Noller, Secondary structure model for bacterial 16S ribosomal RNA: phylogenetic, enzymatic and chemical evidence, Nucleic acids research, 8 (1980) 2275-2293.

[63] H.F. Noller, C.R. Woese, Secondary structure of 16S ribosomal RNA, Science, 212 (1981) 403-411.

[64] H.F. Noller, J. Kop, V. Wheaton, J. Brosius, R.R. Gutell, A.M. Kopylov, F. Dohme, W. Herr, D.A. Stahl, R. Gupta, C.R. Waese, Secondary structure model for 23S ribosomal RNA, Nucleic acids research, 9 (1981) 6167-6189.

[65] W.C. Winkler, A. Nahvi, N. Sudarsan, J.E. Barrick, R.R. Breaker, An mRNA structure that controls gene expression by binding S-adenosylmethionine, Nat Struct Biol, 10 (2003) 701-707.

[66] I.V. Novikova, S.P. Hennelly, K.Y. Sanbonmatsu, 3S: Shotgun Secondary Structure determination for long non-coding RNAs, Methods, (2013).

[67] H. Yao, K. Brick, Y. Evrard, T. Xiao, R.D. Camerini-Otero, G. Felsenfeld, Mediation of CTCF transcriptional insulation by DEAD-box RNA-binding protein p68 and steroid receptor RNA activator SRA, Genes \& development, 24 (2010) 2543-2555.

[68] B. Xu, W.H. Yang, I. Gerin, C.D. Hu, G.D. Hammer, R.J. Koenig, Dax-1 and steroid receptor RNA activator (SRA) function as transcriptional coactivators for steroidogenic factor 1 in steroidogenesis, Mol Cell Biol, 29 (2009) 1719-1734.

[69] S.M. Colley, K.R. Iyer, P.J. Leedman, The RNA coregulator SRA, its binding proteins and nuclear receptor signaling activity, IUBMB Life, 60 (2008) 159-164.

[70] T. Huet, F.A. Miannay, J.R. Patton, S. Thore, Steroid receptor RNA activator (SRA) modification by the human pseudouridine synthase 1 (hPus lp): RNA binding, activity, and atomic model, PLoS One, 9 (2014) e94610.

[71] D.B. McKay, L. Xi, K.K. Barthel, T.R. Cech, Structure and function of steroid receptor RNA activator protein, the proposed partner of SRA noncoding RNA, J Mol Biol, 426 (2014) 1766-1785.

[72] F. Arieti, C. Gabus, M. Tambalo, T. Huet, A. Round, S. Thore, The crystal structure of the Split End protein SHARP adds a new layer of complexity to proteins containing RNA recognition motifs, Nucleic Acids Res, 42 (2014) 6742-6752. 
(a)

(b) (c)

$$
\text { 5'-GCAGAAAUGC U }
$$
3'-CGUCUUUACG U

GCAGAAAUGCUUUUGCAUUUCUGC

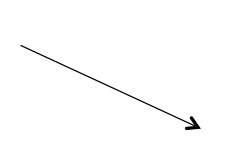

AA UU $G \quad A \quad U \quad C$ A-U A-U 5'-G-C-UUUU-G-C-3'
1. Study single IncRNA system

2. In vitro chemical probing identifies base-paired nts

3. $3 S$ identifies sub-domains

4. Initial secondary structure

5. Initial sequence alignment: synteny

6. Use structure to improve sequence alignment

7. Covariance analysis to help validate helices

8. Focus on validated helices to iteratively improve alignment

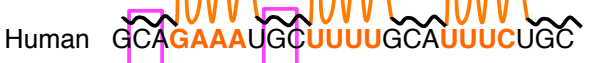

Mouse GgAgAAAUcCUUUUGCAUUUCUGC

Rat GAAGAAAUUCUUUUGCAUUUCUGC

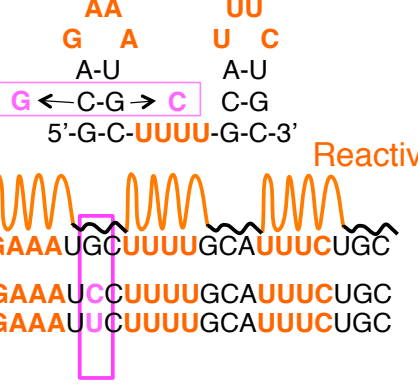


